\title{
La estrategia de la mariposa: poesía y misticismo en Severo Sarduy
}

Denise León

Recebido em: 12 de março de 2019

Aceito em: 12 de abril de 2019
Dra. Denise León (Tucumán, Argentina, 1974) Es Doctora en Letras e Investigadora Adjunta del CONICET. Profesora Asociada de Literatura Hispanoamericana en la Universidad Nacional de Salta, actualmente dirige el proyecto "Ficciones mutantes. Representación y reescritura en las culturas literarias y audiovisuales contemporáneas" y forma parte del proyecto UE "Estrategias para la inclusión socioeducativa" con sede en el INVELEC, CONICET, UNT y del proyecto "Poéticas de la frontera. Nomadismo, diáspora y exilio en la literatura caribeña contemporánea", con sede en la UBA y dirizido por la Dra. Celina Manzoni.

Contato: deniseleon90@gmail.com Argentina 
PALABRAS CLAVE: Severo

Sarduy; literatura caribeña;

mariposeo; poesía mística

KEYWORDS: Severo Sarduy;

Caribbean literature; mariposeo; mystical poetry
Resumen: Los sonetos y las décimas de Un testigo fugaz y disfrazado (1985) de Severo Sarduy, en cuyo análisis se concentra este artículo, funcionan como una lectura oblicua y paródica, como una curiosa retombée de la mística española. A partir de dicho análisis este artículo intenta aquilatar las implicaciones de esa original máquina de lectura construida por el escritor caribeño a partir de la fórmula del "mariposeo". Abstract: The sonnets and the tenths of Un testigo fugaz y disfrazado (1985) by Severo Sarduy, in which analysis this article concentrates, function as an oblique and parodic reading, as a curious retombée of the Spanish mysticism. From this analysis, this article tries to evaluate the implications of that original reading machine built by the Caribbean writer based on the "mariposeo" formula. 
Si escribir es también, o sobre todo, un modo de leer, una reverberación inquietante cuya tarea, como quería Roland Barthes, es liberar eso que está preso, dispersando los significantes, este artículo se propone ensayar una aproximación a los sonetos y décimas de Un testigo fugaz y disfrazado de Severo Sarduy como una lectura oblicua, un eco o una curiosa retombée de la mística española, especialmente de su culminación carmelita. Ahora bien, si intentamos puntualizar el uso que Sarduy hará de la de la mística española, esa "teoría o saber religioso y poemático del amor del alma y Dios" que implica "al mismo tiempo, el problema más genuinamente filosófico de la destrucción" de la "ontología natural de la inteligencia clásica, o griega" (Peńalver, Patricio, 1997, 16) no cabe sino hablar de parodia, desvío o mejor, de robo porque "cuando no hay ninguna lengua conocida disponible, hay que tomar la decisión de robar un lenguaje -como en otra época se robaba un pan-” (Barthes, 2018, 213).

Como apunta Patricio Peñalver en su ya clásico ensayo sobre la mística española, la Escuela Carmelita, y especialmente las obras de Santa Teresa y San Juan de la Cruz, afectan directamente el sentido del ser como presencia o sustancia disponible. La relación que funciona como campo de fuerza en la poesía mística, esto es el vínculo entre un alma enferma de amor y un Dios que hiere y se esconde, no puede sino ser aludida en un lenguaje que se corta y se precipita a una zona sin lenguaje y sin sujeto. En este sentido, no resulta desatendible que, como apunta Peñalver entre otros estudiosos de la mística, tanto el pensamiento contemporáneo como algunas teorías literarias se hayan interesado en volver, de modos inesperados, sobre el 
pensamiento y la poesía mística. Basten como ejemplo Jacques Derrida y su teoría de la Deconstrucción o los teóricos del círculo postestructuralista que Sarduy frecuentó con asiduidad.

Sabemos gracias a los trabajos de Cira Romero y también a las declaraciones del propio Sarduy, del temprano interés de este autor por el pensamiento religioso en sus diversas formas. Se podría hablar, inclusive, de una especie de impureza religiosa en su pensamiento y su escritura que lo distinguen de sus contemporáneos y que lo llevarán a recorrer un camino zigzagueante que va de la teosofía de Jiddu Krishnamurti, a las teogonías orientales pasando por la mística española y la astronomía. En una época "privada de religiosidad" (Sarduy, 1999, 51), Sarduy, al igual que otros intelectuales antes que él, debe inventar sus propios mitos, y lo hará intentando un regreso a manifestaciones religiosas cuyo centro no es una presencia plena sino una oquedad donde se vuelve posible escuchar el “estampido de la vacuidad".

En este artículo, parto de la idea de que lo que le interesa a Sarduy no es tanto la mística como fenómeno histórico sino el deseo sin tregua y sin amparo que sigue sucediendo siempre en los poemas extáticos. La experiencia erótica y deshacedora de la unión mística no es algo remoto en el tiempo sino que está sucediendo justo en el momento en que leemos los poemas. Allí, como diría Edgardo Dobry, "la lengua muerta y la lengua viva establecen su campo de fuerza; porque es en el poema donde la lengua se está haciendo [...]” (en Agamben, Giorgio, 2016, 11). 
Dicho esto, el recorrido que propone el presente artículo se organiza en dos instancias o momentos. En primer lugar, en el apartado "La estrategia mariposa" me interesa detenerme en el movimiento imaginario en el cual Sarduy funda su máquina de lectura. Por cierto, se trata de una estrategia neobarroca que lo lleva a diferir una y otra vez con las formas fijas y con la idea de un yo estable, para buscar una perspectiva oblicua, no frontal, desplazada y móvil. En un segundo momento, en el apartado titulado "Plegar/desplegar/replegar" me concentro en ver cómo funciona esa máquina de lectura en la última etapa en la poesía de Sarduy, compuesta por dos libros breves de sonetos y décimas: Un testigo fugaz y disfrazado (1985) y Un testigo perenne y delatado (1993). Intento leer allí la presencia de la mística española como un lenguaje robado, o una voz que viene de otro tiempo y otro lugar y, exiliada ella misma, provee a Sarduy tanto de una reserva de objetos poéticos como de una determinada retórica. Si bien, por razones de extensión, este ensayo se concentra en el primero de los libros, $U n$ testigo fugaz y disfrazado, vale la pena señalar que, a pesar de estar separados por un lapso temporal de ocho años, hay una estrecha correspondencia entre los dos últimos libros de poemas de Sarduy, vinculados incluso por la figura del testigo sobre la que volveré más adelante, de modo que ambos pueden ser leídos en conjunto, como las tablas de un díptico. Finalmente, en la coda, se ofrecen algunas conclusiones provisorias en torno al recorrido trazado.

Para realizar este movimiento exploratorio, me apoyo fundamentalmente en las consideraciones del propio Sarduy incluidas en su bellísimo 
"Bosquejo para una lectura erótica del Cántico espiritual, seguido de Imitación”, donde explicita su lectura apasionada de la poesía de San Juan de la Cruz y propongo una aproximación al conjunto de sonetos y décimas eróticos de Sarduy como "reflejo, forzosamente deformado, del divino epitalamio" (1999, 246). Incluido en la edición crítica coordinada por Gustavo Guerrero y François Wahl bajo el título de "Últimos poemas”, este bosquejo publicado póstumamente resulta iluminador para el recorrido propuesto, especialmente para dar cuenta de la recreación obsesiva de la pasión por la pérdida y el deshacimiento presentes en la mística hispánica, así como también en la última etapa de la poesía de Sarduy.

Hacia el final del texto, el autor justifica su lectura erótica del Cántico espiritual eligiendo entre tres opciones posibles: la primera -rápidamente descartada - es detener todo comentario, pero eso fijaría la obra, “equivaldría a fosilizarla” (246). La segunda opción sería "arriesgar la exégesis, incluso la menos pertinente" (246) para hacerla vivir. La tercera, finalmente, consiste en:

Mímesis en lugar de lectura; doble y simulacro en lugar de interpretación. Reflejo, forzosamente deformado, del divino epitalamio. Ir en la copia hacia la materialización de las metáforas, explicitar las elipsis, recorrer otra vez el camino: desde el cuerpo enardecido hasta Dios, desde el deseo hasta la fusión con el Uno [sic], desde el objeto a de Lacan hasta el Ser [sic] (Sarduy, 1999, 246).

En el fragmento citado, notamos que Sarduy opta por una combinación de opciones y también que los verbos que elige son verbos que implican 
traslado, desplazamiento, movimiento: ir en la copia, recorrer otra vez el camino, desde el cuerpo enardecido hasta Dios, desde el deseo hasta la fusión, etc. Es posible leer allí una operación estratégica de deslizamiento, un acarreo, un pasearse que le permitirá a Sarduy unir universos distantes como el de la poesía mística y el suyo propio. Es sin duda sintomático que el modo de leer que propone Sarduy -y me refiero a este ir y venir, a este desplazamiento presente tanto en su propia experiencia de exilio y bilingüismo, como en la traducción cultural de experiencias orientales e incluso en su interés por la poesía mística-implica ciertos usos donde el adentro y el afuera se desdibujan y ya no es posible distinguir entre uno y otro. Usando su cuerpo como bisagra, el paseante no se mantiene estático sino que, inevitablemente, se traslada, se desvía y se confunde con la materia paseada, en un movimiento constante de flotación, como el aleteo de una mariposa.

\section{LA ESTRATEGIA MARIPOSA}

Atento a la materialidad de los signos, la máquina de lectura (y de escritura) que Severo Sarduy pondrá a funcionar en Barroco (1974), se apoya en una metáfora que proviene del mundo del sonido: la cámara de eco. Anota el autor en el pórtico de este ensayo dedicado a Roland Barthes:

Las notas que siguen intentan señalar la retombée de ciertos modelos científicos (cosmológicos) en la producción simbólica no científica, contemporánea o no. La resonancia de estos modelos se escucha sin noción 
de contigüidad ni de causalidad: en esta cámara, a veces el eco precede a la voz.

Historia caduca leída al revés; relato sin fechas: dispersión de la historia sancionada.

Boomerang: trazando la agrimensura de la cámara de eco, el mapa de la repercusión de ciertos modelos, cuya retombée se detecta, mostrarán su reverso: ni esquema puro, operante, sin base, ni unidad científica mínima, sino - patente en el círculo de Galileo, o en la teoría del big bang de Lemaître- núcleo imaginario, marca teológica $(1999,1197)$.

Si nos detenemos con atención en el fragmento citado, resulta sintomático no sólo que Sarduy elija una metáfora del mundo del sonido, de la voz, una materialidad que se desvanece y que es, al mismo tiempo, presencia y ausencia, para dar cuenta de la resonancia de los modelos científicos en la producción simbólica, sino también el hecho de que tome un concepto en otra lengua, el francés, para fundar su teoría. El concepto de retombée es más que un envío a otra lengua, gesto revelador de una dislocación territorial o de su condición desplaza de exiliado, nos remite también a sus múltiples conexiones con las vanguardias literarias y artísticas francesas de los sesenta -reunidas en torno a la revista Tel Quel-y también a su amistad con Roland Barthes; datos fundamentales para comprender desde dónde lee Sarduy.

El sonido y el sentido, parece decirnos el autor cubano, son dos intensidades que construyen una máquina poética, donde se lee o se escucha al revés. Es decir, de modo invertido. E insiste en la no linealidad de la trayectoria planteada: habla de boomerang, de reverso, de repercusión, de 
impureza. Más que reproducir los modelos o las matrices, los visita, los invoca, los acaricia o los homenajea en un movimiento tenaz y flotante como la trayectoria de una mariposa cuya presencia anuncia, al mismo tiempo, un movimiento perpetuo de cierre y abertura, un latido.

Esta compleja operación intelectual llevada a cabo por Sarduy, quien desde la autofiguración de "heredero" se ocupa de leer a contracorriente la tradición latinoamericana para fundar el neobarroco, no fue siempre comprendida y valorada por la intelectualidad latinoamericana de izquierda que sólo pudo leer allí un gesto superfluo o banal. Muy lejos de esa interpretación y en sintonía con la hipótesis que nos proponemos trabajar aquí, Rafael Rojas en La Vanguardia peregrina (2013), un conjunto de ensayos deslumbrantes sobre escritores cubanos cuya obra se construyó no solo en sino por el exilio, vuelve sobre las palabras con las que, en 1971, Roberto Fernández Retamar intentara capturar la poética de Severo Sarduy, para dispersar su significado y volver a leerlas desde otra perspectiva. Como es ya conocido, en su mentado Calibán, Retamar califica de "mariposeo neobarthesiano" la producción de Sarduy, aludiendo despectivamente a su sexualidad y a su relación con la vanguardia francesa, específicamente con Roland Barthes.

Si bien el ensayo de Retamar se concentra sobre todo en reformular la dicotomía sarmientina de civilización y barbarie y dirige mayormente sus críticas e invectivas contra Carlos Fuentes, a quien considera "una de las más destacadas figuras entre los nuevos escritores latinoamericanos que se han propuesto elaborar, en el orden cultural, una plataforma 
contrarrevolucionaria” (1971, 60), el comentario al pasar sobre Sarduy resulta significativo para el presente ensayo. Entiendo que retomando la frase mordaz de Retamar, lanzada en el marco de invectivas contra aquellos intelectuales vinculados a la revista Mundo Nuevo, es posible establecer una especie de reverberación fascinante o una cámara de eco, en un sentido similar al que el propio Sarduy le diera a este término. Así, el emblema de la mariposa y su movimiento, despojados ya de connotaciones negativas, me permitirán indagar esa operación en bucle que lleva a cabo la poética sarduyana con la mística española. Particularmente, me interesa trabajar con la imagen de la falena, esa mariposa nocturna que persigue la luz hasta fundirse con ella, como una heráldica de su producción que, lejos de la inconstancia o la imprecisión, se construye como una ética a costa de las formas fijas o estables.

Rafael Rojas nos ofrece un comienzo posible cuando, en el ensayo ya citado, recupera y reivindica la idea del mariposeo como un ojo o un lente que le permite captar la potencia y la originalidad del método de escritura de Sarduy y también, por supuesto su relación con Barthes. Rojas señala que la invectiva de Retamar se enmarca en una serie de ataques que la oficialidad intelectual cubana dirigió al círculo de intelectuales en torno a la revista Mundo Nuevo, y que, de algún modo, dice más sobre la localización ideológica y estética de la intelectualidad revolucionaria que sobre Sarduy, cuya estrategia neobarroca no podría causar más que rechazo y extrañeza en el este grupo. 
La movilidad, el vagabundeo, la variación son lo propio de la mariposa. "La aventura vanguardista y cosmopolita de Sarduy" (Rojas, 2013, 80) tiene que ver con ese movimiento, con esos desplazamientos del deseo y también con la lectura atenta que Barthes hizo de Charles Fourieur, quien concibió el mariposeo como una persecución infinita y gozosa, como "una verdadera estrategia del deseo concebido como utopía política" (Huberman, 2007, 28). Justamente, en Roland Barthes por Roland Barthes (1975), el crítico francés expresa de un modo concentrado y brillante el imaginario estético que lo aproxima a Sarduy y distancia a ambos de las exigencias sensibles del socialismo cubano. Anota en la entrada titulada no casualmente "La seńorita burguesa":

En plena agitación política, toca el piano, pinta acuarelas: todas las falsas ocupaciones de una señorita burguesa del siglo XIX. Invierto el problema: ¿qué de las prácticas de la señorita burguesa de antaño excedía su feminidad y su clase? ¿cuál era la utopía de esas conductas? La señorita burguesa producía inútilmente, estúpidamente para sí misma, pero producía ${ }^{1}$ era su forma propia de gastar (Barthes, 1975, 62).

Si leemos con detenimiento el fragmento, podemos notar que la autofiguración barthesiana de señorita burguesa, próxima a la de Lady SS de Sarduy, trabaja lo femenino como una situación minoritaria. Siempre en algún margen, sea de la sociedad, del lenguaje, o del deseo, se trata de una producción que genera incomodidad en un contexto político y cultural que

1 El énfasis es del original. 
reivindica una acción política ligada a la masculinidad y la violencia. Hay una radical otredad en esa producción femenina que desagrada e incomoda al discurso patriarcal. Tal como afirma Anne Carson en su ensayo sobre el género del sonido, para el orden patriarcal hay una afinidad "natural femenina" con todo lo que es inmaduro, informe, abierto, desbordante (Carson, 2019). Como bien nota Barthes, hay algo del orden del exceso en esas prácticas, un modo propio de la señorita burguesa que tiene que ver con el gasto y la inutilidad de lo que se prodiga sin motivo aparente como el derroche de la mariposa.

\section{Plegar/DESplegar/Replegar}

Los sonetos y décimas que me propongo analizar pertenecen a una etapa poética en la producción de Sarduy que, por momentos, parece haber resultado desconcertante para la crítica, quien leyó allí o bien una etapa de repliegue o de "retracción métrica" (Sánchez Robayna, 1999, 1564) respecto de su producción anterior considerada más experimental; o bien "un tributo que el soneto debía pagar para poder introducirse de nuevo en la modernidad poética del español” (Sánchez Robayna, 1999, 1567). Intentaremos aquí una hipótesis diferente.

En "El ideograma y el deseo (La poesía de Severo Sarduy)", Sánchez Robayna, advierte que luego de Big Bang (1974), la poesía de Sarduy entra en una nueva fase y afirma que esa nueva fase estará "no determinada por el uso de nuevas formas, sino por su nueva radicalidad: por su modo más estricto de beber en las fuentes barrocas y por su regreso simbólico al país 
natal" (Sánchez Robayna, 1999,1561). A pesar de esta salvedad, a medida que avanza el análisis, el crítico canario se detiene sobre todo en un análisis del modo en que la forma soneto y la forma décima gravitan en la poesía de Sarduy, así como también considera central la analogía erotismo-barroco en su poética. El crítico lee "la violencia lingüística en materia erótica" como un intento de "romper el aura neoclásico-garcilacista del soneto para volver a introducirlo en la lengua poética española" $(1999,1567)$.

Creo que hay más. En Poesía bajo programa, esa conferencia pronunciada en 1991 en una de sus últimas apariciones públicas, que luego fuera publicada póstumamente como plaquette y finalmente incluida al final de sus libros de poemas en la edición crítica de sus obras, Sarduy insiste en que poesía bajo programa "no significa en absoluto volver únicamente a las formas tradicionales de poesía: no es eso en lo más mínimo" (1999, 253). La libertad total de que gozan el pintor y el poeta ha generado "una crisis de sentido", por lo tanto, afirma es necesario volver a "formas controladas". Sarduy se propone, entonces, inventar formas a partir de ciertos modelos u obsesiones: la cosmología, los sonetos de Mallarmé y "el único escritor que conozco bastante bien y que leo todos los días. Es raro que pase un día sin que la lea. Mi devoción por ella es, pues, religiosa a través de la textualidad" (1999, 257): Santa Teresa de Ávila.

Resulta evidente, entonces, a partir de las afirmaciones del propio autor en distintas intervenciones, así como las menciones explícitas en sus poemas, que la poesía mística española (especialmente la de Santa Teresa y la de San Juan de la Cruz) le aporta un peculiar espesor a esta última etapa 
poética. Esto no significa necesariamente que estemos frente a una poesía religiosa, pero es claro que, como señala Rafael Rojas, hay una búsqueda de espiritualidad dislocadora que impregna la poética de Sarduy desde el comienzo. En esta última etapa específicamente, Sarduy encuentra en la mística espańola, una forma y un lenguaje que vienen de otro tiempo y convergen en la breve fulguración de sus sonetos y décimas. Como anuncia el último terceto del soneto dedicado a Luce López Baralt, reconocida estudiosa del misticismo español y especialmente de la obra de San Juan de la Cruz:

Dejemos de esa heráldica que viajen

los símbolos, el mudo abecedario: agua y sed, brasa y luz, cuerpo y sudario $(1999,208)$.

La aventura que propone la mística es, sin dudas, una aventura corporal que implica no sólo la creación de un espacio interior sino un deseo voraz y nocturno en medio de una engañosa visibilidad, así como una sed imposible de satisfacer. Citado por Luce López Baralt en El sol a medianoche. La experiencia mística: tradición y actualidad (2017) Williams James resume las características centrales de la experiencia extática: es intuitiva (predomina en ella lo afectivo sobre lo intelectual), efímera e inefable. Por último, anota López Baralt, la experiencia es infusa y pasiva: "se puede ayudar a inducir por ejercicios de concentración o meditación pero es totalmente gratuita y deja al sujeto con un sentido de impotencia total, como si se encontrara ante un Poder frente al que no tuviera la posibilidad de ejercer 
su voluntad" (13). El éxtasis místico, como el erótico, son experiencias "deshacedoras", donde el sujeto se pierde, deja de ser, para fundirse con aquello que ama. Y si, como afirma Peñalver, la raíz de la mística española o de su culminación carmelita, es una recreación inventiva del poema erótico-místico del Cantar de los cantares, como en un juego de espejos, Sarduy construye sus propias variaciones del "divino epitalamio":

EL ÉMBOLO brillante y engrasado

embiste jubiloso la ranura

y derrama su blanca quemadura

más abrasante cuanto más pausado.

Un testigo fugaz y disfrazado

ensaliva y escruta la abertura

que el volumen dilata y que sutura

su propia lava. Y en el ovalado

mercurio tangencial sobre la alfombra

(la torre embadurnada penetrando, chorreando miel, saliendo entrando)

descifra el ideograma de la sombra:

el pensamiento es ilusión: templando

viene despacio la que no se nombra (202). 
Tanto en la noche monástica que imagina Sarduy como en este soneto, de cuyo quinto verso surge el título del poemario, los cuerpos arden, envueltos de deseo. La "quemadura abrasante", la "lava que sutura" o el "mercurio tangencial", aproximan pasión y dolor. Comparable a un flechazo, "el émbolo brillante y engrasado" embiste ante un testigo que reduce su acción al mínimo: ensalivar y escrutar la abertura. El Amado inscribe su presencia y su ausencia en el cuerpo del amante "saliendo, entrando", lacerándolo. Hemos dicho ya que una de las características de la experiencia mística es que se trata de un momento "sin verbo, de quejido y exaltación, al borde del susurro, que se confunde con el jadeo" (Sarduy, 1999, 243). El exceso del goce místico o erótico implican la disolución del sujeto que se pierde, se disgrega y queda balbuceando ante la sombra. Al igual que para las teogonías orientales, fundamentales en la obra de Sarduy, la mística se apoya en la idea de que el mundo exterior es una ilusión que, tarde o temprano, confiesa su impostura. La acción sobre el mundo es una tentación frente a la cual el místico tiene que afirmar su estado de gracia a través de un acto apasionado de pérdida y deshacimiento. La mística, afirma Peñalver, es una experiencia extraordinaria del ser, o mejor, en "contra del ser" $(1997,18)$. Y recuerda oportunamente que el Carmelo fue una orden fundada en Palestina en el siglo XIII con un sentido más oriental que romano.

Se produce así en la poesía mística una singular coincidencia de nihilismo y práctica poética que los sonetos y las décimas de Sarduy retoman, aproximando de un modo vertiginoso lo erótico y lo mortuorio. Como 
en el caso del carpe diem horaciano hay una voluntad casi pedagógica en los poemas que reiteran la proximidad del goce y la muerte recordando esa cualidad apasionada y efímera de las falenas nocturnas que van inevitablemente, como los místicos, hacia las llamas que las devoran. Así, el soneto citado se cierra con una máxima que se repetirá con variaciones a lo largo del poemario: "el pensamiento es ilusión: templando/ viene la que no se nombra”. En el siguiente soneto, también sobre el final leemos: "Muerte que forma parte de la vida/Vida que forma parte de la muerte" $(1999,202)$ o en la tercera décima del mismo libro: "Divierte/ el placer así obtenido/por el sendero invertido:/ más vida cuanto más muerte" (211).

Esta "muerte que da vida" atraviesa los poemas de Santa Teresa y San Juan de la Cruz. Se trata de un continuo desvivirse en el deseo del Amado que jamás se alcanza o se agota. Muerte y vida se aproximan peligrosamente en el famoso poema de Santa Teresa a quien no morir para estar en Dios hace vivir en agonía. Así describe Sarduy la trayectoria del deseo en su ensayo sobre San Juan y otra vez la falena agita sus alas: "Más el deseo se desplaza, deambula detrás de su objeto y, pasado el momento de saciedad, de nuevo lo solicita" (1999, 245). El movimiento inevitable y a la vez imposible del amante, como el del ciervo que huye y a la vez hiere en San Juan, es tal vez la cifra de la impropiedad, de lo que permanece inapropiable para siempre, despedida de toda caza y de toda voluntad de apropiación:

Renuncia a tu cuidado, bien lo sé: tras ese dolor que tu embestida aqueja, 
en alivio y placer muda la queja, más sosegada cuando más penetras.

Cerveza transmutada o sidra añeja, del oro tibio la furiosa recta su apagado licor suma y proyecta sobre el cuerpo deseoso que festeja tanto derrame. A bálsamos o ardides que atenúen la quema de tu entrada nunca recurras. Mientras menos cuides

unjas, prevengas, o envaselinada disimules, mejor. Para que olvides el mudo simulacro de la nada (204).

Podría hablarse de una teatralidad de los sonetos y las décimas de $U n$ testigo fugaz y disfrazado donde cada poema se construye a modo de escena. Allí, el yo lírico nos exhorta a comportarnos de distintas maneras y nos da una serie de consejos o instrucciones. La idea de someter la meditación religiosa o la capacidad amatoria a un trabajo metódico, no es nueva. En un juego que evoca tal vez la preparación ascética y el afán didáctico de los místicos, Sarduy le aconseja a su posible ejercitante un trabajo de negación sostenida: renuncia a tu cuidado, nunca recurras, menos cuides. Hay una 
suspensión de la acción, un vaciamiento voluntario, una inoperosidad en el sentido que Giorgio Agamben le diera a este término, donde el placer implica destrucción y gasto, en la medida en que es consumido como el alimento. "Esta comunión, quizás por su doble pertenencia a lo sagrado y a lo sexual, priva: encanta, fascina, y desposee de todo conocimiento, de toda identidad", agrega Sarduy en su ensayo sobre San Juan.

La entrega al arrebato sin taza ni medida del alma enferma de amor en su búsqueda no voluntarista de la pasividad, de abandono - que en los místicos ha sido leída como la imitación del desamparo y la entrega de Cristo en la cruz,- puede leerse también en relación al goce sexual a partir de la pasividad y el dolor propios del sadismo. No casualmente Sarduy insiste en que la aventura del Cántico espiritual se inicia con una ausencia "hiriente" y se expresa en una queja que ningún idioma puede enunciar y que limita con la muerte. Se trata de una "brusca laceración" (1999, 243) que, comparable a un flechazo, alumbra un gozo que tiene mucho de letal. Así, le indica el yo lírico a su ejercitante:

No acudas a linimento, alcanfor, miel o saliva, que atenúen el momento de más ardor. No se esquiva con ardid, ni se deriva esa quema: se convierte en su contrario. Divierte 
el placer así obtenido

por el sendero invertido:

más vida cuanto más muerte (211).

Resulta claro ya en este punto de nuestro recorrido que Sarduy se ubica frente a la poesía mística como frente a una reserva de objetos poéticos que estuvieron vivos alguna vez y tuvieron un sentido, para apropiárselos en un gesto que no puede sino ser paródico. Porque como señala Agamben a propósito del poeta italiano Giorgio Caproni: "acaso en todo ámbito, pero notoriamente en la lengua, todo uso es un gesto polar: por una parte, apropiación y hábito; por la otra, despojamiento y no-identidad. Usar [...] significa tanto servirse de como acostumbrar a $(2016,174)$. Así, en los sonetos y las décimas, Sarduy se sirve de la pasión mística para instalar, a partir del doble sentido y los juegos de palabras, un desnivel que pone a funcionar esa pulsión cuasi pornográfica y burlesca junto a la más refinada espiritualidad. Podría afirmarse que nuestro poeta manipula tanto "los consuelos de la religión" como los de la parodia:

\author{
OMÍTEMELA más, que lo omitido \\ cuando alcanza y define su aporía, \\ enciende en el reverso de su día \\ un planeta en la noche del sentido.
}

A pulso no: que no disfruta herido, 
por la flecha berniniana o por manía de brusquedad, el templo humedecido (de Venus, el segundo). Ya algún día

lubricantes o medios naturales pondrás entre los bordes con taimada prudencia, o con cautela ensalivada

que atenúen la quema de tu entrada: pues de amor y de ardor en los anales de la historia la nupcia está cifrada (201).

En este soneto, que el propio Sarduy califica en su conferencia en Canarias de "pornográfico y funerario" $(1999,260)$ vemos cómo la "omisión" -sinónimo de la estrategia barroca de la elipsis-, así como el "sendero invertido" con el que cerraba la décima anterior, tienen claras alusiones sexuales. Del mismo modo, esta nupcia de "amor y ardor" se vincula a los "anales" de la historia. De allí que podamos afirmar que Sarduy escribe su propia versión, extensión o comentario del "divino epitalamio" místico, de acuerdo a la orientación de su deseo. Si pensamos que esta poesía, inevitablemente profana, se ubica en un contexto histórico, social y cultural muy diferente al de la mística, esa relación entre el alma enferma de amor y un Dios que hiere y se sustrae, un deus absconditus que es buscado apasionadamente, sólo puede ser accesible en clave paródica. 
Agamben, siguiendo a Scaligero, propone que la parodia deriva de la rapsodia, porque había un momento en que los rapsodas eran interrumpidos y entraba en escena un nuevo grupo que, ya sea con un afán lúdico o para distraer a los espectadores, "ponía de revés todo cuanto los había precedido... Por eso llamaron paroidous [parodias] a estos cantos, porque junto y más allá del argumento serio insertaban otras cosas ridículas" (2016, 221). Así, quedan fijadas para Agamben las dos características fundamentales de la parodia que iluminan el análisis de los sonetos y las décimas sarduyanas: la dependencia de un modelo preexistente que es transformado y la conservación de elementos formales en los que se insertan contenidos nuevos e incongruentes.

Ahora bien, si Dios tal como lo entendieron los Carmelitas del siglo XVI ha desaparecido de los textos de Sarduy, donde el umbral que separa sagrado y profano se ha vuelto indistinguible, resulta significativo para este artículo que, algo de esa persecución excesiva y apasionada se mantenga en el tejido vivo de sus poemas. El misticismo crea un espacio interior, virtualmente inaccesible, relacionado con el secreto y los excesos que debe protegerse del poder. En el caso de Sarduy, cuya escritura siempre estuvo atenta a las operaciones estratégicas para forzar los límites del cuerpo y el sexo, como afirma Gustavo Guerrero en su ensayo "Sobre la piel: Reinaldo Arenas y Severo Sarduy en contacto" (2017), lo que la escritura penetra no son ya los distintos recintos que conducirían, de forma escalonada, al contacto con lo divino, sino que "la noche oscura del alma" se transforma en la opacidad de cuerpo deseado pero imposible de agotar. 
Aún así, el lector tiene la impresión de que los sonetos y las décimas se apilan unos sobre otras, como si remitieran a algo que falta, que no puede sino faltar. Una ausencia que se duplica o se agiganta en los tiempos profanos en los que los textos de Sarduy respiran entrecortadamente. Ya no se persigue el paso efímero del un dios escondido e hiriente sino su huella silenciosa. Frente al numen, que según Barthes es el gesto silencioso con que los dioses pronuncian el destino humano, procedido de una larga mirada, el poeta esgrime el canto, la frase, la página, roba una lengua muerta y sostiene la impostura con su propio cuerpo:

EL PASO no, del dios, sino la huella escrita entre las líneas de la piedra verdinegra y porosa. Aún la hiedra retiene las pisadas, aún destella

de su cuerpo el contorno sobre rojos sanguíneos o vinosos: en los vasos fragmentados dispersos. No los pasos del dios, sino las huellas; no los ojos:

la mirada. Ni el texto, ni la trama de la voz, sino el mar que los decanta. En su tumba - las islas ideograma 
de esa página móvil donde tanta frase, ni bien grabada, se derrama -, sumergida tu estatua ciega, canta (204).

Si, como afirma Barthes en Sade, Fourier, Loyola [1971] (1997), "la Iglesia funda su autoridad en la palabra, la fe es audición”, en los textos de Sarduy Dios ha dejado de hablar con sus criaturas. Sarduy trata explícitamente sobre este desamparo, sobre la indiferencia como el modo de ser de lo divino en el fragmento III de "El estampido de la vacuidad", una colección de fragmentos publicada póstumamente. Hacia el final, afirma: "Les pedimos, en definitiva, que renuncien a su esencia y sean en la nuestra, que es la mirada. Pero es inútil. No abandonan jamás esa noche, ese hueco negro que, para siempre, los devoró" $(1999,106)$. Frente al silencio de los dioses, la locuacidad humana. Ante la caída de lo divino y de lo humano hacia una zona incierta y ya sin sujeto (quien enuncia los versos es una estatua ciega) lo único que resta es el canto. Pero, como nos recuerda Barthes "el aparato fonatorio es también el aparato oscular. Al pasar a la posición erguida, el hombre descubrió que tenía la libertad de inventar el lenguaje y el amor” (182). Así, frente a la retracción de los dioses, el poeta elige como última resistencia, arder y practicar de forma espuria una forma poética antigua, casi muerta. 


\section{CODA}

En el recorrido propuesto, he recurrido al emblema de la mariposa para dar cuenta de dos cuestiones centrales: por un lado, el estilo, la máquina de lectura (y de escritura) que construye Sarduy y por otro, su relación con la mística española. Sabemos que el dispositivo neobarroco creado por el autor caribeño funciona canibalizando y consumiendo discursos que provienen de lenguajes y sistemas culturales diferentes. Lejos de un código literario lineal o clasificado, recurre al movimiento, al desborde hacia otras regiones de la cultura, el sujeto y el lenguaje. Sintomáticamente, el autor parte de una metáfora del mundo de la voz, "la cámara de eco", y de la idea del goce sonoro como modos de rechazo al tedio de una lectura adiestrada o academicista. En este movimiento de flotación, en este pasearse por distintos lenguajes y universos culturales reside la originalidad y la potencia de la escritura de Sarduy.

Si bien, como señala Rojas, Sarduy recibió el comentario de Retamar como una ofensa homófóbica y, al ensayar su defensa en el ensayo "El heredero" (1999, 1413) no reivindica o naturaliza el concepto de mariposeo, tampoco abandonó sus coordenadas estéticas ni su método de lectura. Las mariposas reaparecerán en La simulación, ese ensayo brillante publicado en 1982, tres ańos antes de la salida de Un testigo fugaz y disfrazado. En La simulación Sarduy trabaja sobre esa pulsión letal del disfraz que conecta el exceso y el anhelo de una realidad otra en el insecto, el místico y el travesti, todos de algún modo criaturas de la noche. Se trata de aventuras somáticas donde la particularidad reside en que los cuerpos serán el soporte de las 
obras. Lo letal, dirá Sarduy, "no es a su vez más que una forma extrema, el exceso de despilfarro de sí mismo" $(2013,233)$.

En un segundo momento del análisis, la figura de la mariposa me permitió vincular las intensidades de la poesía de Sarduy con las de la mística española. Como notas a pie de un texto lejano en el tiempo, pero central en la poética del autor, los sonetos de Un testigo fugaz y disfrazado reescriben elementos fundantes de la experiencia mística, esto es ser efímera, inefable, afectiva y pasiva. En La imagen mariposa, Didi Huberman comparte este interés por la mariposa como emblema en una serie de autores que, como es sabido, formaron parte de las coordenadas estéticas de Sarduy: me refiero a Fourier, Bataille, Callois y Lacan, entre otros. Se trata de intelectuales que se ocuparon de algún modo de zonas "nocturnas" de la cultura y el deseo. En el mencionado ensayo, Huberman seńala que la mariposa es reconocida como una criatura del deseo y recuerda que Eros suele ser representado con una mariposa en la mano. Pero se trata de un deseo "abocado a su pura pérdida” (Huberman, 2007, 85), poseído por la destrucción. En la figura de la falena nocturna deseo y muerte se aproximan de modo excesivo, vertiginoso, como en la poesía mística.

En este sentido, considero que al leer la mística española como un lenguaje o una intensidad que le permite a Sarduy trabajar en su poesía la imposibilidad apasionada de aproximarse a aquello a lo que lo que desea unirse, propongo una interpretación no menos reductora que otras posibles. Marcados por el duelo y por la burla, en los sonetos y las décimas de Un testigo fugaz y disfrazado puede escucharse la retombé de una voz que, 
aquejumbrada y gozosa, peregrina en la noche o el desierto de la ausencia divina. El goce, lo sabemos desde Barthes, no es lo que satisface al deseo, sino lo que lo excede, lo desconcierta, lo deriva. El goce funciona como la llama que atrae, inevitablemente, a la mariposa y en cuyo chisporreoteo los poemas de Sarduy buscan, inúltimente, la llama viva del Ser.

\section{REFERENCIAS BIBLIOGRÁAICAS:}

Agamben, Giorgio. El final del poema. Estudios de poética y literatura, Buenos Aires: Adriana Hidalgo, 2016.

Barthes, Roland. Sade, Fourier, Loyola, Madrid: Cátedra, [1971] 1997.

Barthes, Roland. Lo obvio y lo obtuso. Imágenes, gestos, voces, Buenos Aires: Paidós, 1986 [1982].

Barthes, Roland. Roland Barthes por Roland Barthes, Buenos Aires: Eterna Cadencia, 2018 [1975].

Didi Hiberman, Georges. La imagen mariposa, Barcelona: Edición El Mudito, 2007.

Dobry, Edgardo. "Poéticas inesperadas: Agamben y la poesía", en Agamben, Giorgio. El final del poema. Estudios de poética y literatura, Buenos Aires: Adriana Hidalgo, 2016. 7-15.

Guerrero, Javier. "Sobre la piel: Reinaldo Arenas y Severo Sarduy en contacto", en Cuadernos de Literatura Vol. XXI n 42, Julio-Diciembre, 2017. 1551-1570.

López Baralt, Luce. El sol a medianoche. La experiencia mistica: tradición y actualidad, Madrid: Trotta, [1996] 2017.

Peñalver, Patricio. La mistica española (siglos XVI y XVII), Madrid: Akal, 1997.

Rojas, Rafael. La vanguardia peregrina. El escritor cubano, la tradición y el exilio, México: Fondo de Cultura Económica, 2013. 
Sánchez Robayna, Andrés. "El ideograma y el deseo (La poesía de Severo Sarduy), en Severo Sarduy, Obra completa, Madrid: Archivos. 1999. 1551-1570.

Sarduy, Severo. Obra completa. Tomos I y II, Edición crítica a cargo de Guerrero, Gustavo y Wahl, François, Madrid: Archivos, 1999.

Sarduy, Severo. Obras III. Ensayos, México: Fondo de Cultura Económica, 2013. 